\title{
Leveraging IT for Distance Education: An Interdisciplinary Graduate Program on the Internet
}

\author{
Zeynep Onay \\ Middle East Technical University, Turkey
}

onay@ba.metu.edu.tr

\begin{abstract}
Distance education through the Internet represents a paradigm shift in higher education. The implementation of an information technology (IT) enabled teaching and learning environment necessitates the redesign of conventional structures. This paper addresses some of the issues involved in the design and delivery of an Internet-based interdisciplinary graduate program in Informatics at Middle East Technical University in Turkey. The aim of the paper is to contribute to the development of a number of guidelines for leveraging the use of IT in distance education programs at universities.
\end{abstract}

Keywords: asynchronous learning, interdisciplinary program, distance education

\section{Introduction}

Middle East Technical University (METU) is the first university in Turkey to implement an Internet-based learning environment, introducing the concept of any time, any place (asynchronous) learning in a traditional higher education institution. Since 1998, the University has been delivering a wide range of individual courses as well as a certificate program through the Internet to a diverse clientele. This year, the University launched Informatics Online, the first IT enabled graduate degree program in Turkey. The program has two distinguishing features. First, all courses are delivered through the Internet. Second, the program is interdisciplinary, combining courses from computer engineering, business administration, industrial engineering, and electrical and electronics engineering, reflecting the multidisciplinary nature of informatics as a field.

This paper describes the evolution of asynchronous learning at METU and presents the features of the Informatics graduate program, followed by a discussion of the administrative, academic and technological issues that need to be

Material published as part of this proceedings, either on-line or in print, is copyrighted by the author with permission granted to the publisher of Informing Science for this printing. Permission to make digital or paper copy of part or all of these works for personal or classroom use is granted without fee provided that the copies are not made or distributed for profit or commercial advantage AND that copies 1) bear this notice in full and 2) give the full citation on the first page. It is permissible to abstract these works so long as credit is given. To copy in all other cases or to republish or to post on a server or to redistribute to lists requires specific permission from the author. resolved for integrating IT enabled distance education programs in universities.

\section{The METU Experience}

METU took a centralized, institutional approach for the development of its asynchronous learning network: METU-Online (Onay, 1999). This allowed the consolidation of scarce resources and facilitated the coordination of activities. The University assigned the task of establishing METU-Online to the Informatics Institute. The Institute is an interdisciplinary graduate school responsible for all research, planning, development and implementation activities concerning distance education through the Internet.

At the Informatics Institute a team composed of faculty from the departments of business administration, computer engineering, electrical and electronics engineering and education launched the METU-Online project in May 1998. The software tool for course preparation and delivery has been developed at the Institute and is being maintained by the Institute's Distance Education Laboratory. METU-Online is the institutional delivery platform for the University's online courses. The courses are from the undergraduate and graduate curricula of various departments within the University, ranging from history to astronomy (Middle East Technical University, 2000a). All courses have been developed by resident faculty, and are being delivered to around 2000 students each semester. The mode of delivery varies among courses, ranging from 


\section{IT for Distance Education}

fully asynchronous course conduct, to the use of online material as a supplement to full class contact hours.

In addition, METU-Online enables the efficient use of scarce faculty resources to teach very large audiences. At METU, all students are required to take an introductory computer literacy course during their first year. This means that approximately 4000 freshmen have to be taught each year. To meet this requirement, the Informatics Institute designed the Introduction to Information Technologies and Applications course (IS 100) and the course is being delivered through METU-Online to 2000 students each semester.

In February 1999, the Informatics Institute launched the Informatics Certificate Program online to train instructors from other Turkish universities to design and deliver introductory computer literacy courses such as IS 100 in their own universities. Instructors from various universities have been participating to the program while carrying out their duties in their respective institutions, without traveling to METU and interrupting their normal work schedules.

The Informatics Online graduate program is the latest addition to the Institute's expanding portfolio of IT applications in higher education.

\section{The Informatics Online Program}

The spread and scope of information systems and technologies in all sectors of the economy present organizations with new challenges and opportunities. Organizations need professionals who are able to respond to these challenges and exploit strategic opportunities. It is to address this need that the Informatics Institute developed the Informatics Online graduate program (Middle East Technical University, 2000b).

Informatics is a domain where the theory and practice of a number of disciplines merge. It amalgamates the fields of computer engineering, business administration, electrical and electronics engineering and industrial engineering. The program presents an integrated multidisciplinary approach that aims to equip participants with the skills necessary to foresee and use the full potential of information systems and technologies in the context of their own working environment.

The program is intended for working professionals drawn from diverse industries and professional backgrounds. Thus, the interdisciplinary nature of the program is also reflected to the composition of its participants. An objective of the program is to give participants a better understanding of the priorities and requirements of other stakeholders in their working environment, with a view to reduce the communication gap between various groups within the organization. Having a clientele coming from different areas of expertise allows the program to achieve this objective. Moreover, through interaction with fellow participants, students are exposed to a rich and varied breadth of ideas and approaches.

The curriculum emphasizes the interdisciplinary nature of informatics and consists of a set of compulsory core courses and a number of elective courses designed especially to strike a balance between theory and practice. The full course list is provided in Appendix 1. Courses like the Information Systems Online Group Project and the Graduate Seminar provide students the opportunity to collaborate in a teamwork setting and develop effective solutions to real life problems. In addition, all students are required to complete a major term project before graduation. The program requirements are shown in Table 1.

\begin{tabular}{|l|l|}
\hline Courses & Credits \\
\hline 5 core courses & 3 credits each \\
\hline 5 elective courses & 3 credits each \\
\hline Graduate Seminar & Non-credit \\
\hline $\begin{array}{l}\text { Informatics Term } \\
\text { Project }\end{array}$ & 4 credits \\
\hline
\end{tabular}

Table 1. Informatics online program requirements

All courses in the program are delivered through the Internet. Face-to-face contact is only required for two days at the beginning of each term, to introduce students and faculty and the components of each course, and two days at the end of each term for final exams. Communication and collaboration among students and instructors is achieved by using both asynchronous (e-mail, forums/discussion lists) and synchronous (chat, whiteboard) tools. Student performance is assessed based on the results of final exams 
and self-tests administered on the Web, assignments, projects, and contribution to chats, seminars and forums.

\section{Issues and Challenges}

Delivering courses on the Internet involves much more than a change of medium, from face-to-face classroom interaction to an environment free of time and place constraints (Bourne 1998; Hanna 1998; Pelton 1997). The successful integration of the online learning paradigm in universities requires the resolution of a number of administrative, academic and technological issues. This is especially true in the case of interdisciplinary programs where traditional hierarchical barriers must be removed to develop effective 'learner informing systems' (Cohen, 1999). The challenge must be approached at two different levels: the institution and the program.

\section{The institution level}

Incorporating new modes of learning requires the revision of institutional policies and procedures (Harris \& DiPaolo 1999, Reid 1999). The conformance of online courses and programs to the University's existing statutes, rules and regulations has to be established. Matters that have been considered at METU include: alignment with the admission criteria set out by the Academic Rules and Regulations for Graduate Programs at Middle East Technical University, and the establishment of new administrative procedures for remote registration and payment of tuition fees. In addition, measures have been established for the distribution of revenues among the various contributors to Internet-based courses and programs.

Motivating faculty to take part in the University's online initiative is another issue that has to be addressed at the institution level. Specific incentives need to be developed. These can be in the form of giving release time for preparing online courses, reducing faculty teaching load for traditional courses, and counting contributions to IT enabled distance education towards academic promotion.

A key concern in online programs is the maintenance of academic standards. At METU, the existing regulations require all new programs to be first approved by the University senate, followed by the Higher Education Council of Turkey. In order to ensure the equivalence of traditional and Internet-based programs, an additional phase has been introduced at METU. This phase consists of the accreditation of all online courses and programs by an Accreditation Committee directly reporting to the President of the Uni- versity. Accordingly, each course in the program goes through a two-step accreditation procedure. The first step takes place at the end of course preparation and before the course is delivered online. The course is reviewed to establish its conformance to the University's Guidelines and Standards for the Design of Online Courses. The second step of accreditation takes place at the end of the semester in which the course has been delivered. The Accreditation Committee assesses the course in terms of learning outcomes and effectiveness in using the various instructional tools incorporated in METU-Online. At this stage, the Committee also appoints an external reviewer for assessing the course content.

Using IT for distance education also brings forth issues related to the management of the underlying technology in order to ensure the continuous operation, maintenance and reliability of the system. Moreover, support services have to be provided to individual faculty as well as students. Currently, staff at the Informatics Institute are responsible for the management of the technology supporting Internetbased courses and programs, including system administration, software and hardware upgrades, user support, accounts and passwords, and other security issues.

The digital age challenges the hitherto established principles of intellectual property and copyright. Current legislation in most countries is inadequate to clarify the situation for online course material and this affects institutions involved in distance education through the Internet in two ways. First, the ownership of individual course content has to be established. Second, intellectual property has to be protected. METU had to review its copyright policy, not only for the material produced in the courses, but also for the material used to produce the courses.

\section{The program level}

The departure from the traditional 'lecture hour' and 'classroom' concepts represents a shift in educational philosophy and instructional design, as the emphasis moves from 'teaching' to 'learning', leading to a student-centered, rather than instructor-based system. Therefore, the attributes of the delivery platform and the format of presentation for online learning are of primary importance at the program level. NET-Class, the software platform for the Informatics graduate program has been designed and developed at the Informatics Institute. It is a learning management system that incorporates a number of features to facilitate student learning as well as class management. 


\section{IT for Distance Education}

NET-Class provides a secure environment for creating and delivering courses. It allows students and instructors to follow courses using their preferred Web browsers. All system utilities are provided through a graphical user interface. The system has three user views: the instructor, system administrator and student views. Access is authorized by the system and the related view is presented to the user. The tools incorporated for each view are presented in Figure 1, Figure 2 and Figure 3 respectively.

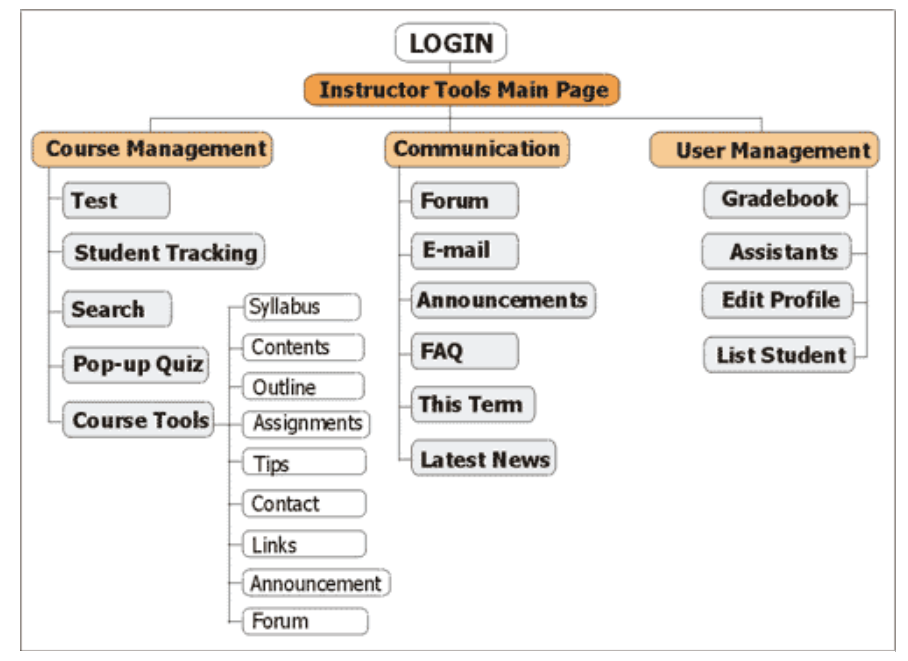

Figure 1: System tools for instructors

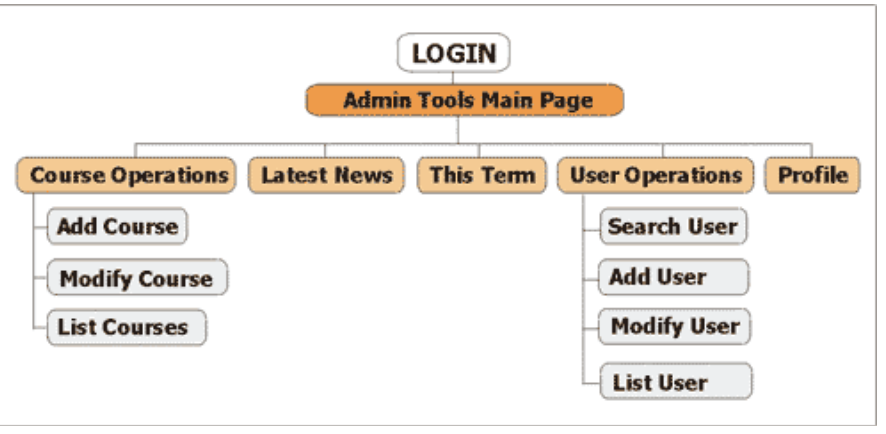

Figure 2: Tools for system administration

Instructors can organize course content, apply tests, quizzes, use the automatic grading utility, send mail, administer the threaded discussions, and view student access rates graphically with the tools provided by the system. NETClass includes templates to produce core parts of a course like the syllabus, announcements, and assignments. These templates ensure ease of navigation and consistency in the format of presentation throughout the program.

The system administrator is able to add/modify courses, register students, change their passwords, and monitor re- source usage. Students can take online tests and exams, see their results in the grade book, and perform searches in the course material.

At METU, another issue that had to be addressed at the program level is the provision of Internet services to students. The Informatics Institute offers each participant to the online program an unlimited Internet account through TR-NET, an Internet Service provider directly connected to the University's ATM network. This facilitates access and allows fast communication among users. The Institute also maintains a high level of technical support for instructors and students enrolled in the program.

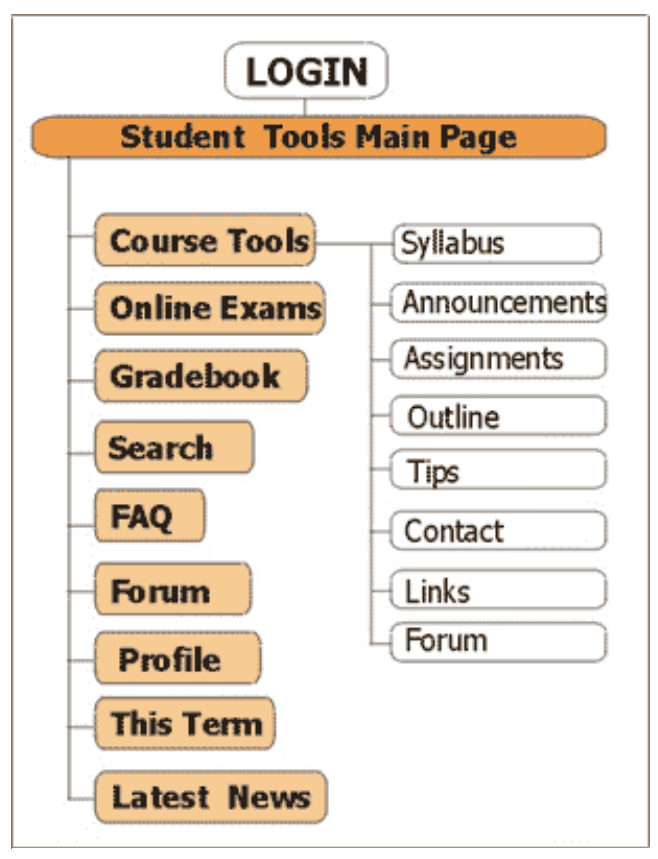

Figure 3: System tools for students

As the program is interdisciplinary its success is dependent on the Institute's ability to sustain the support of the departments and faculty delivering the courses. Coordination has to be maintained in order to expand the choice of electives and keep the curriculum up-to-date, in line with the latest developments in information systems and technologies.

\section{Conclusion}

The use of IT in distance education presents universities with new opportunities to reach wider audiences and strengthen effectiveness in teaching. The Informatics Institute at Middle East Technical University has been 
delivering courses through the Internet to on-campus as well as off-campus students for the past three years. Recently, to meet the growing need for professionals responsive to the challenges of a dynamic informationbased society, the Institute launched its online Informatics graduate program.

The METU experience demonstrates that the integration of IT enabled distance education in traditional higher education establishments necessitates the resolution of a number of administrative, academic and technological concerns both at the institution level and at the program level.

This paper illustrates some of the issues that are critical for the effective implementation of Internet-based distance education in universities, and provides a framework for the establishment of guidelines to leverage IT in distance education.

\section{References}

Bourne, J. R. (1998). Net-Learning: Strategies for On-Campus and OffCampus Network-enabled Learning. Journal of Asynchronous Learning Networks., 2 (2), 70-87. Accessed December 14, 2000 at ntip://www.aln.org/ainweb/journal//aln_volzissuez.htm+tbourne

Cohen, E. (1999). Reconceptualizing Information Systems as a Field of the Transdiscipline Informing Science: From Ugly Duckling to

Swan. Journal of Computing and Information Technology, 7 (3), 213-219. Accessed December 14, 2000 at http://1nform.nu/Whatsis.htm.

Hanna, D. E. (1998). Higher education in an era of digital competition: emerging organizational models. Journal of Asynchronous Learning Networks, 2 (1), 66-95. Accessed December 14, 2000 at http://www.aln.org/alnweb/journal/vol2_issue1/hanna.htm.

Harris, A.D., \& DiPaolo, A. (1999). Institutional Policy for ALN. Journal of Asynchronous Learning Networks, 3 (1), 1-7. Accessed December 14, 2000 at http://www.aln.org/alnweb/journal/jalnvol3issue1.htm\#Institutional Policy for ALN

Middle East Technical University. (2000a). Home page, METU-Online, Accessed December 14, 2000 at nttp://www.11.metu.edu.tr/metuonline

Middle East Technical University. (2000b). Home page, Informatics Online. Accessed December 14, 2000 at http://10n.11.metu.edu.tr

Onay, Z. (1999). Building an Internet-Based Learning Environment in Higher Education: Learner Informing Systems and the Life-Cycle Approach. Informing Science: International Journal of an Emerging Discipline, 2 (2), 45-52. Accessed December 14, 2000 at http://inform.nu/Articles/Vol2/v2n2index.htm
Pelton, N. (1997). Cyberlearning vs. the university: an irresistible force meets an immovable object. IEEE Engineering Management Review, Fall, 110-113.

Reid I.C. (1999). Beyond Models: Developing a University Strategy for Online Instruction. Journal of Asynchronous Learning Networks, 3 (1), 19-31. Accessed December 14, 2000 at http://www.aln.org/alnweb/journal/jaln-vol3issue1.htm\#Beyond Models: Developing a University Strategy for Online Instruction

\section{Appendix 1: Informatics Graduate Program Course List}

\section{Core courses}

ION 501 Introduction to Information Systems

ION 502 Introduction to Software Engineering

ION 503 Database Concepts and Applications

ION 504 Computer Networking for Information Systems

IION 505 Information Systems Online Group Project

ION 590 Graduate Seminar (Non-credit)

ION 592 Information Systems Design Project

\section{Elective courses}

ION 514 Multimedia

ION 525 Artificial Intelligence

ION 526 Introduction to Neural Networks

ION 528 Image Processing Algorithms

ION 535 Introduction to Medical Informatics

ION 542 Information Technology and Business Processes

ION 545 Software Quality Management

ION 551 Managing Technology and Innovation

ION 561 Fundamentals of Simulation

ION 562 Optimization

\section{Biography}

Zeynep Onay is an Associate Professor of Operations Management and Information Systems at the Department of Business Administration, Middle East Technical University (METU), Turkey. She is a founding member of the Informatics Institute at METU, served as Associate Director at the Institute and is a member of the Institute's Executive Committee. She is also a member of the university's Accreditation Committee for online courses and programs. Zeynep Onay has been actively involved in the 


\section{IT for Distance Education}

groundwork, development and implementation of METUOnline since 1997. She took part in the curriculum design of the Institute's online Certificate Program in Informatics as well as the Informatics Online graduate program. She has prepared and delivered courses through METU-Online since 1998. Dr. Onay has developed and taught the Introduction to Information Systems compulsory course in the Informatics Online graduate program in collaboration with Prof. Dr. S. Bilgen from the Department of Electrical and Electronics Engineering at METU. 